\title{
Antioxidant activity of Giant Black Garlic
}

\author{
D. Kim, S. J. Jung, S. Y. Cheon, Y. J. Cho, M. H. Tae, K. H. Kim and H. S. Yook \\ Dept. of Food and Nutrition, Chungnam National University, Daejeon 305-764, Korea
}

This study was carried out to investigate the antioxidant activities of giant black garlic from giant fresh garlic. Giant black garlic was manufactured and fermented by Jumbo Garlic (Co., Ltd., Yongin, Gyeonggi-do, Korea). Giant black garlic and giant fresh garlic were extracted in $50 \%$ ethanol $^{(1)}$ and Freeze-Dried powder were dissolved in $70 \%$ DMSO (Dimethyl sulfoxide). FRAP values(Ferric reducing antioxidant potential activity), Total phenol contents, DPPH radical scavenging activity were investigated. FRAP values of samples was measured by the method Benzie and Strain ${ }^{(2)}$ and total phenol contents of samples was measured by the method Folin-Ciocalteu and DPPH radical scavenging activity of the samples was measured by the method of Blois ${ }^{(3)}$ with a slight modification.
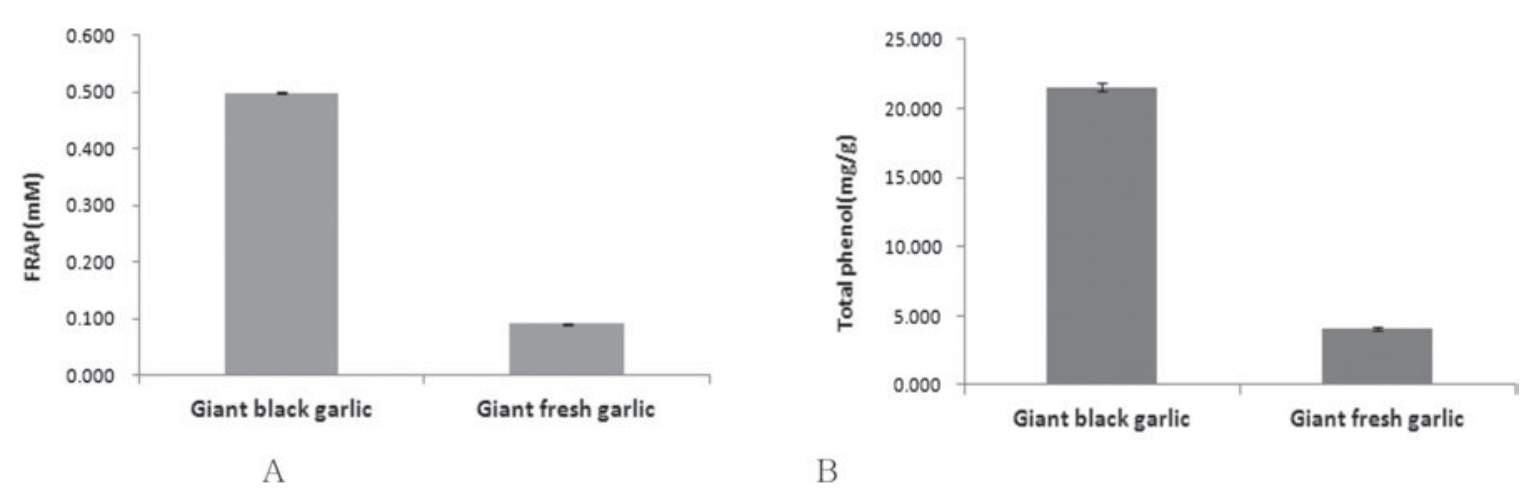

Fig. 1. FRAP(A) and Total phenol(B) of giant black garlic and giant fresh garlic.

Table 1. DPPH radical scavenging activity of giant black garlic and giant fresh garlic

\begin{tabular}{lr}
\hline & \multicolumn{1}{c}{$\mathrm{IC}_{50}(\mathrm{mg} / \mathrm{mL})^{1}$} \\
\hline Black & $1.238 \pm 0.546^{2,3(3)}$ \\
Fresh & $52.360 \pm 0.925^{(\mathrm{a})}$ \\
\hline${ }^{1}$ Amount required for $50 \%$ reduction of $0.2 \mu \mathrm{M} \mathrm{DPPH}$ \\
after 30 min. \\
${ }^{2}$ Values are mean \pm SD. \\
${ }^{3}$ Different letter within a same row(a-b) differ significant \\
$(p<0.05)$.
\end{tabular}

FRAP values of giant black garlic and giant fresh garlic were $0.499 \pm 0.003$ and $0.091 \pm 0.001 \mathrm{mM}$, respectively. FRAP values of giant black garlic was five times higher more than giant fresh garlic (Fig 1. A). Fig 1. B shows that the total phenol contents in giant black garlic and giant fresh garlic were $21.523 \pm 0.278$ and $4.130 \pm 0.125 \mathrm{mg} / \mathrm{g}$ and total phenol of giant black garlic was five times higher more than giant fresh garlic. $\mathrm{IC}_{50}$ of $\mathrm{DPPH}$ radical scavenging activity of giant black garlic and giant fresh garlic were $1.238 \pm 0.546$ and $52.360 \pm 0.925 \mathrm{mg} / \mathrm{mL}$ and antioxidant activity of giant black garlic was higher than giant fresh garlic whereas $\mathrm{IC}_{50}$ of giant black garlic was lower than giant fresh garlic (Table 1). The result support the view that giant black garlic is effective to antioxidant activities and can become good health food.

1. Shin JH, Choi DJ, Lee SJ, Cha JY, Sung NJ (2008) J Korean Food Sci Nutr 37(8), 965-971.

2. Benzie IFF \& Strain JJ (1996) Anal Biochem 230, 70-79.

3. Blois MS (1958) Nature 181, 1199-1200. 